\title{
Naturally Occurring Mutations in the Human 5-Lipoxygenase Gene Promoter That Modify Transcription Factor Binding and Reporter Gene Transcription
}

\author{
K.H. In, ${ }^{\star \S}$ K. Asano, ${ }^{\star \S}$ D. Beier, ${ }^{\star \S}$ J. Grobholz, ${ }^{\star}$ P. W. Finn, ${ }^{\star \S}$ E.K. Silverman, ${ }^{\star \S}$ E.S. Silverman, ${ }^{\star \ddagger \S} \|$ T. Collins, ${ }^{\ddagger \|}$ A.R. Fischer, ${ }^{\star \S}$ \\ T.P. Keith," K. Serino, , S.W. Kim, ${ }^{\star \S}$ G.T. De Sanctis, ${ }^{\star \S}$ C. Yandava, ${ }^{\star \S}$ A. Pillari, ${ }^{\star \S}$ P. Rubin, ${ }^{\star \star}$ J. Kemp, ${ }^{\star \star}$ E. Israel, ${ }^{\star \S}$ \\ W. Busse, ${ }^{* \star}$ D. Ledford, ${ }^{\star *}$ J.J. Murray, A. Segal, ${ }^{\star *}$ D. Tinkleman, ${ }^{\star \star}$ and J.M. Drazen ${ }^{\star \S}$ \\ $*$ Department of Medicine, and ${ }^{\ddagger}$ Department of Pathology, Brigham and Women’s Hospital, Boston, Massachusetts 02115; ${ }^{\circledR}$ Department of \\ Medicine, and "Department of Pathology, Harvard Medical School, Boston, Massachusetts 02115; "Department of Human and Molecular \\ Genetics, Genome Therapeutics Corporation, Waltham, Massachusetts 02154; and **The Zileuton Study Group, Abbott Laboratories, \\ Abbott Park, IL 60064-3500
}

\begin{abstract}
Five lipoxygenase (5-LO) is the first committed enzyme in the metabolic pathway leading to the synthesis of the leukotrienes. We examined genomic DNA isolated from 25 normal subjects and 31 patients with asthma (6 of whom had aspirin-sensitive asthma) for mutations in the known transcription factor binding regions and the protein encoding region of the 5-LO gene. A family of mutations in the $\mathrm{G}+\mathrm{C}$-rich transcription factor binding region was identified consisting of the deletion of one, deletion of two, or addition of one zinc finger (Sp1/Egr-1) binding sites in the region 176 to $147 \mathrm{bp}$ upstream from the ATG translation start site where there are normally $5 \mathrm{Sp} 1$ binding motifs in tandem. Reporter gene activity directed by any of the mutant forms of the transcription factor binding region was significantly $(P<0.05)$ less effective than the activity driven by the wild type transcription factor binding region. Electrophoretic mobility shift assays (EMSAs) demonstrated the capacity of wild type and mutant transcription factor binding regions to bind nuclear extracts from human umbilical vein endothelial cells (HUVECs). These data are consistent with a family of mutations in the 5-LO gene that can modify reporter gene transcription possibly through differences in Sp1 and Egr-1 transactivation. (J. Clin. Invest. 1997. 99: 1130-1137.) Key words: leukotrienes • asthma
\end{abstract}

\section{Introduction}

Five lipoxygenase (5- $\mathrm{LO}^{1}$; arachidonate: oxygen 5-oxidoreductase, E.C.1.13.11.34, 5-LO) is the first committed enzyme in the biosynthetic pathway leading to the production of the

Address correspondence to Jeffrey M. Drazen, M.D., Respiratory Disease Division, Brigham and Women's Hospital, 75 Francis Street, Boston, MA 02115. Phone: 617-732-7420. FAX: 617-732-7421.

Received for publication 24 October 1996 and accepted in revised form 17 December 1996.

1. Abbreviations used in this paper: CAT, chloramphenicol acetyltransferase; Egr-1, a zinc finger binding protein; EMSA, electrophoretic mobility shift assay; HUVEC, human umbilical vein endothelial cell; 5-LO, five-lipoxygenase; PMA, phorbol myristate acetate; Sp1, a zinc finger binding protein; SSCP, single-stranded conformational polymorphism; SSLP, simple sequence length polymorphism.

J. Clin. Invest.

(C) The American Society for Clinical Investigation, Inc. 0021-9738/97/03/1130/08 \$2.00

Volume 99, Number 5, March 1997, 1130-1137 leukotrienes (1-3). Through reactions catalyzed by 5-LO, arachidonic acid is sequentially converted to 5-hydroperoxyeicosatetraenoic acid and then to leukotriene $\mathrm{A}_{4}$. It has been previously established that the human gene encoding 5-LO contains 14 exons and 13 introns encompassing over $82 \mathrm{~kb}$ of genomic DNA (4). In the 5' flanking region of the gene both positive and negative regulatory regions as well as a transcription factor binding region have been identified. These latter regions have been shown to possess elements important for 5-LO gene expression as indicated by chloramphenicol acetyltransferase (CAT) reporter constructs (5). These observations provide reason to believe that there may be naturally occurring mutations that could either modify 5-LO gene transcription or modify the putative protein derived from translation of 5-LO mRNA. To test this hypothesis all 14 exons, as well as the previously identified positive and negative regulatory regions and transcription factor binding region, of the 5-LO gene were scanned for mutations using genomic DNA derived from normal and asthmatic subjects. A number of mutations were identified. Among the mutations noted, a family of alleles with variation in the number of tandem zinc finger binding proteins ( $\mathrm{Sp} 1$ and Egr-1) in the transcription factor binding region were identified; these alleles were shown to be associated with diminished reporter assay activity and altered transcription factor binding suggesting their potential roles in regulation of 5-LO gene expression.

\section{Methods}

Patient materials. Fresh whole blood was obtained from 25 patients (20 males) with asthma, according to American Thoracic Society (ATS) criteria, whose only asthma treatment was inhaled $\beta$-agonists. The forced expiratory volume in the first second, $\mathrm{FEV}_{1}$, in these patients averaged $62.3 \%$ of predicted levels and their mean age was 39.1 yr. Fresh whole blood was also obtained from 6 patients with aspirinsensitive asthma whose clinical characteristics have been previously detailed (6) and 25 individuals (11 males) who had no history of significant medical illness, had no history of asthma or atopy, and had negative skin tests to a panel of 12 common aeroallergens. Buffy coat was separated, resuspended in RPMI, layered onto a Percoll gradient, and immortalized using Epstein-Barr virus by standard techniques $(7,8)$.

DNA was obtained by buccal brushing from an additional 81 patients with mild to severe asthma (none with aspirin-sensitive asthma by history), who received their asthma care at the Longwood Medical Area Adult Asthma Center; these samples were used to confirm the presence of the mutations noted in the genomic DNA isolated from the immortalized cell lines noted above. In these patients the diagnosis of asthma, according to American Thoracic Society criteria, was confirmed by chart review.

Mutation identification. Genomic DNA within the 14 exons, the known positive regulatory region (854 to $931 \mathrm{bp}$ upstream from the ATG start site), and negative regulatory regions (292 to 727 and 1,557 
to 1,844 bp upstream from the ATG start site) was screened for mutations using single-stranded conformational polymorphism (SSCP) analysis according to the method of Orita et al. (9), with minor modifications; the oligonucleotide primers used are listed in Table I. The kinase labeling reaction was carried out by mixing $3.0 \mu \mathrm{l}$ of $\left[\gamma^{-32} \mathrm{P}\right] \mathrm{ATP}$

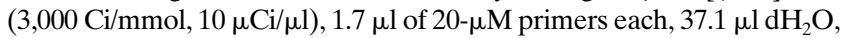
$5.0 \mu \mathrm{l}$ of $10 \times \mathrm{T} 4$ polynucleotide kinase buffer, and $1.5 \mu \mathrm{l}$ of T4 polynucleotide kinase $(10 \mathrm{U} / \mu \mathrm{l})$. The mixture was incubated at $37^{\circ} \mathrm{C}$ for $45 \mathrm{~min}$ and then at $66-70^{\circ} \mathrm{C}$ for $10 \mathrm{~min}$. The PCR reaction volume was $12.5 \mu \mathrm{l}$ containing 100-250 ng of genomic DNA in the presence of $1 \mu \mathrm{l}$ of ${ }^{32} \mathrm{P}$-labeled primers ( $0.13 \mu \mathrm{M}$ each $)$, dNTPs ( $0.4 \mathrm{mM}$ each $), \mathrm{MgCl}_{2}$ $(1.6 \mathrm{mM})$, and Taq DNA polymerase $(0.5 \mathrm{U})$.

Amplification of the highly $\mathrm{G}+\mathrm{C}$-rich transcription factor binding region (88 to 212 bp upstream from the ATG start site) required different PCR conditions. A reaction volume of $20 \mu \mathrm{l}$ was used containing $250 \mathrm{ng}$ of genomic DNA in the presence of $2 \mu \mathrm{l}$ of ${ }^{32} \mathrm{P}$-labeled primers $(0.2 \mu \mathrm{M}$ of each primer $)$, dATP $(0.2 \mathrm{mM}), \mathrm{dCTP}(0.2 \mathrm{mM})$, of $\operatorname{dTTP}(0.2 \mathrm{mM})$, a $3: 1$ ratio of dGTP to 7 -deaza-dGTP $(0.2 \mathrm{mM}), 1 \mu \mathrm{l}$ of DMSO, $2 \mu \mathrm{l}$ of Taq extender PCR additive (Stratagene Inc., La Jolla, CA), and Taq polymerase (1 U). PCR was performed (PTC100TM programmable thermocycler; MJ Research, Inc., Waltham, MA) for 35 cycles (each cycle was $94^{\circ} \mathrm{C}$ for $1 \mathrm{~min}, 56-62^{\circ} \mathrm{C}$ for $1 \mathrm{~min}$, and $72^{\circ} \mathrm{C}$ for $1 \mathrm{~min}$ ).

PCR products were diluted (1:10) in a stop solution (95\% formamide with $20 \mathrm{mM}$ EDTA, $0.05 \%$ [wt/vol] xylene cyanol, $0.05 \%$ [wt/ vol] bromophenol blue). Denaturation was carried out at $95^{\circ} \mathrm{C}$ for 10 min and samples were immediately loaded on a nondenaturing acrylamide gel (MDE; AT Biochem, Malvern, PA). Electrophoresis was performed at $4{ }^{\circ} \mathrm{C}$ and at $40 \mathrm{~W}$ for 5-6 $\mathrm{h}$, the gel dried and exposed to $\mathrm{x}$-ray film.

Simple sequence length polymorphism (SSLP). Because sequence analysis showed mutations which modified the number of Sp1 and Egr-1 binding motifs the transcription binding region (212 to $88 \mathrm{bp}$ upstream from the translation start site) of genomic DNA from a number of individuals was analyzed by SSLP (10). SSLPs were carried out either using ${ }^{32} \mathrm{P}$-labeled primers or including $\left[\alpha{ }^{-35} \mathrm{~S}\right] \mathrm{dATP}$ in the PCR reaction mix. PCR amplification reactions for the ${ }^{32} \mathrm{P}$-labeled primers were performed similar to the method used for SSCP. The amplification of genomic DNA that involved the inclusion of $\left[\alpha-{ }^{35} \mathrm{~S}\right] \mathrm{dATP}$ was carried out according to the following method. The PCR mixture in $25 \mu \mathrm{l}$ contained $500 \mathrm{ng}$ of genomic DNA, PCR buffer (Boehringer Mannheim, Mannheim, Germany), $2.5 \mathrm{mM} \mathrm{MgCl}_{2}, 200 \mu \mathrm{M}$ dCTP and dTTP, $50 \mu \mathrm{M}$ dGTP, $150 \mu \mathrm{M}$ 7-deaza-dGTP, $10 \mu \mathrm{M}$ dATP, $6.25 \mu \mathrm{Ci}$ of $\left[\alpha-{ }^{35}\right.$ S $]$ dATP (DuPont-New England Nuclear, Boston, MA), 10 pmoles of each primer, $5 \%$ DMSO, and $1.5 \mathrm{U}$ of Taq polymerase. The PCR conditions were: $6 \mathrm{~min}$ at $94^{\circ} \mathrm{C}$, followed by 31 cycles of $94^{\circ} \mathrm{C}$ for $15 \mathrm{~s}, 62^{\circ} \mathrm{C}$ for $23 \mathrm{~s}$, and $72^{\circ} \mathrm{C}$ for $30 \mathrm{~s}$. Chain elongation was continued after the last cycle for 5 min. $10 \mu \mathrm{l}$ of PCR product was mixed with $5 \mu$ l of stop solution. Samples were denatured at $95^{\circ} \mathrm{C}$ for $5 \mathrm{~min}$, and $6 \mu \mathrm{l}$ of each sample was loaded on a $6 \%$ denaturing acrylamide gel; the gel was run at room temperature for $2.5 \mathrm{~h}$ at $60 \mathrm{~W}$. Gels were dried and exposed to $\mathrm{x}$-ray film as required (11).

DNA sequencing. To identify the mutations noted, the PCRamplified products were sequenced directly or cloned in a PCR compatible vector (TA; Invitrogen Corp., San Diego, CA). The primers used for sequencing were the same as those used in the PCR-SSCP analysis. The PCR mixture contained $2 \mu \mathrm{M}$ of both primers, $0.2 \mathrm{mM}$ of dNTP mixture, $0.5 \mu \mathrm{g}$ of genomic DNA, and $1.25 \mathrm{U}$ of Taq polymerase in a total volume of $50 \mu \mathrm{l}$. PCR was performed for 30 cycles (each cycle was $94^{\circ} \mathrm{C}$ for $30 \mathrm{~s}, 56-62^{\circ} \mathrm{C}$ for $30 \mathrm{~s}$, and $72^{\circ} \mathrm{C}$ for $1 \mathrm{~min}$ ). The PCR products were purified using a commercially available PCR product purification kit according to the manufacturer's instructions (Promega Corp., Madison, WI); the products so purified were used as template DNA for direct cycle sequencing. Primers were labeled using $\mathrm{T} 4$ polynucleotide kinase; the mixture was incubated at $37^{\circ} \mathrm{C}$ for $30 \mathrm{~min}$ and then heated to $90^{\circ} \mathrm{C}$ for $10 \mathrm{~min}$ to inactivate the kinase. 1 $\mu \mathrm{l}$ of ${ }^{32} \mathrm{P}$-labeled sequencing primer was mixed with template DNA (60-80 fmol), $4.5 \mu \mathrm{l}$ of reaction buffer ( $300 \mathrm{mM}$ Tris- $\mathrm{HCl}, \mathrm{pH} 9.0 ; 50$ $\mathrm{mM} \mathrm{MgCl}_{2} ; 300 \mathrm{mM} \mathrm{KCl}$ ), and $1.25 \mathrm{U}$ of Taq DNA polymerase in a total volume of $36 \mu \mathrm{l} ; 8 \mu \mathrm{l}$ of the labeling mixture was then transferred to each of the four terminal tubes containing $2 \mu \mathrm{l}$ of the termination mixture (containing deoxy dNTP) as described in the dsDNA

Table I. PCR Primers Used in Mutation Identification and Sequencing of the 5-Lipoxygenase gene

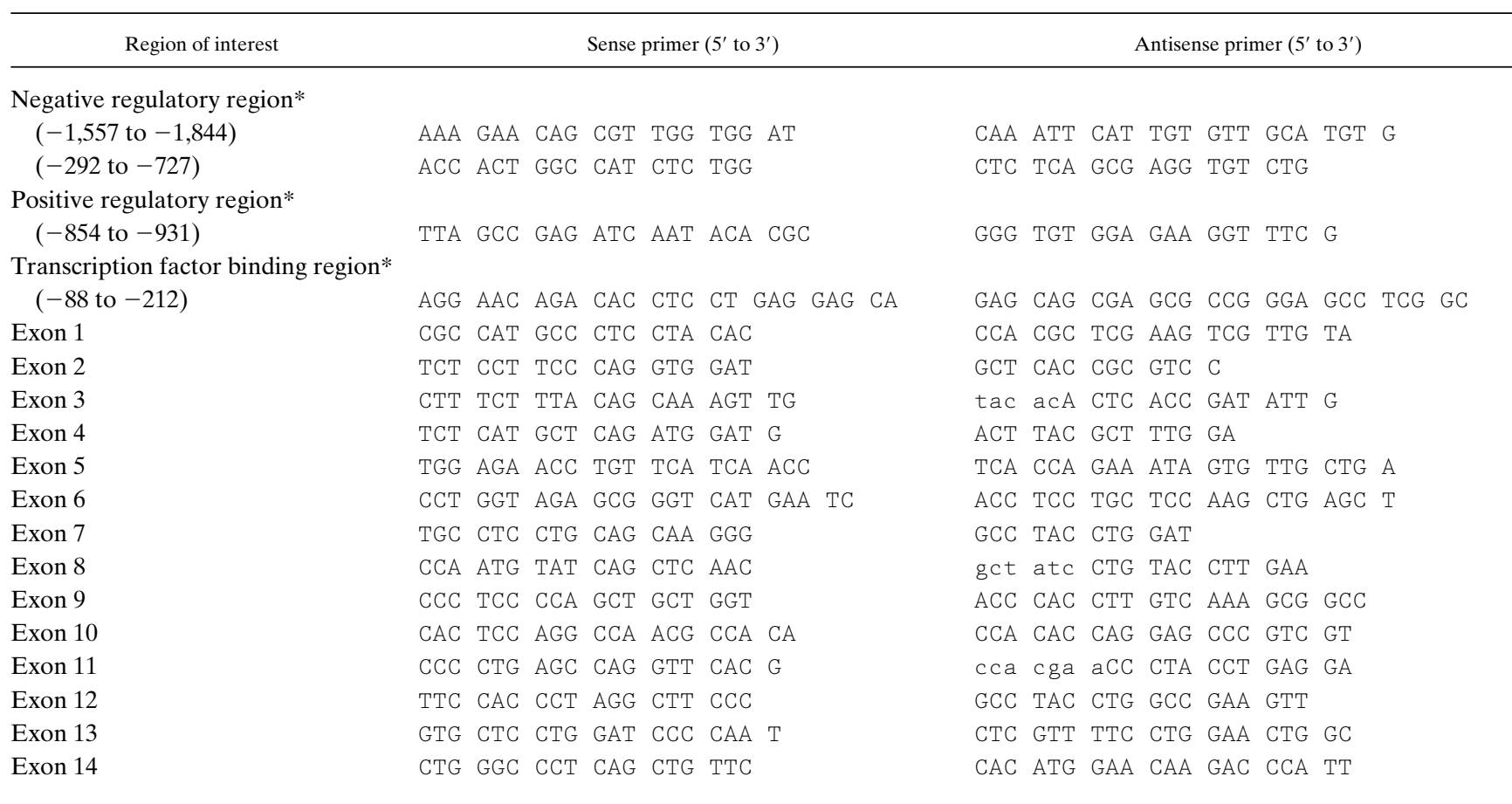

*Position is reference to the ATG translation start site as +1 . 
Cycle Sequencing System (GIBCO BRL, Gaithersburg, MD). PCR amplification was carried out after 20 cycles of a denaturation step at $94^{\circ} \mathrm{C}$ for $30 \mathrm{~s}$, an annealing step at $56^{\circ} \mathrm{C}$ for $30 \mathrm{~s}$, and an extension/termination step at $72^{\circ} \mathrm{C}$ for $1 \mathrm{~min}$, followed by 10 cycles of a denaturation step at $94^{\circ} \mathrm{C}$ for $30 \mathrm{~s}$ and an extension/termination step at $72^{\circ} \mathrm{C}$ for $1 \mathrm{~min}$. The reaction was stopped and the product loaded onto a $6 \%$ sequencing gel. To sequence both alleles from heterozygous individuals, DNA from two clones (wild type and mutant) from TA cloning that showed migration differences on a $3 \%$ agarose gel were sequenced. Automated sequencing was performed on a DNA sequencer (model ABI 373S; Applied Biosystems, Inc., Foster City, CA) according to sequencing chemistry used by this instrument.

CAT reporter assays. Plasmids 5LO-CAT were constructed using the pCRII vector (Invitrogen Corp.) or the pCAT-Enhancer vector (Promega Corp.) as indicated by each respective manufacturer. PCRamplified segments from genomic DNA isolated from individuals who harbored the various mutations identified in the 5-LO gene promoter were subcloned into the pCRII (p5LOpCRII) vector. (In wild type DNA the amplified segment was $280 \mathrm{bp}$ and consisted of the 5-LO DNA 294 to 15 bp upstream from the ATG translation start site; the size of the amplified fragment differed among the various polymorphic forms of DNA.) The 5-LO upstream region was isolated from p5LOpCRII by restriction enzyme digestion with HindIII and $\mathrm{XbaI}$ and ligated into the pCAT-Enhancer vector to generate p5LOCAT. HeLa cells were cultured in 60-mm diam culture dishes in modified Eagle's medium supplemented with $10 \%$ (vol/vol) FCS. p5LO-CAT was transfected into these cells when they reached 50$70 \%$ confluence using Transfectam (Promega Corp.). Cells were harvested $48 \mathrm{~h}$ after transfection, lysed and lysates analyzed for CAT activity by standard techniques $(12,13)$. The transfections were internally controlled by cotransfection with the plasmid vector pXGH5 containing the human growth hormone (HGH) structural sequence (Nichols Institute, San Juan Capistrano, CA). Human growth hormone activity of the cell supernatant was used to normalize the CAT results for transfection efficiency using the HGH-TGES 100T kit (Nichols Institute) according to the manufacturer's instructions.

Oligonucleotide synthesis, purification, and radiolabeling. Oligonucleotides for supershift analysis and electrophoretic mobility shift assay (EMSA) using recombinant proteins were synthesized on a 392 DNA/RNA Synthesizer (Applied Biosystems, Inc., Foster City, CA). Complementary strands were annealed, purified by nondenaturing polyacrylamide gel electrophoresis, and end-radiolabeled with $\left[\gamma^{-}{ }^{32} \mathrm{P}\right] \mathrm{ATP}$ (DuPont-NEN) using T4 polynucleotide kinase (New England BioLabs Inc., Beverly, MA).

Nuclear extract preparation. Compartmental extracts from human umbilical vein endothelial cells (HUVECs) grown in tissue culture were prepared by a modification of the method by Dignam et al. (14). At confluence, monolayers were washed twice with PBS at $4^{\circ} \mathrm{C}$ and collected, using a rubber policeman, in a 50-ml conical tube on ice. Cells were pelleted, lysed, and the nuclei pelleted; the nuclei were resuspended, lysed, vortexed, and centrifuged (15). Supernatants containing nuclear proteins were removed, immediately frozen on dry ice, and stored at $-80^{\circ} \mathrm{C}$.

Recombinant proteins. Recombinant Egr-1 (zinc finger region) was generously provided by Dr. F.J. Rauscher III (Wistar Institute of Anatomy and Biology, University of Pennsylvania, Philadelphia, PA). Samples were stored at $-80^{\circ} \mathrm{C}$ in dilutions of 1:10, 1:50, 1:200, and 1:500 containing $25 \mathrm{mM}$ Hepes-KOH, $\mathrm{pH} 7.5,100 \mathrm{mM} \mathrm{KCl}, 10$ $\mathrm{mM} \mathrm{ZnSO}_{4}, 0.1 \%$ Nonidet P-40, 1 mM DTT, and 50\% glycerol. Recombinant Sp1 (Promega Corp.), purified from HeLa cells infected with recombinant vaccinia virus containing human Sp1 cDNA, was stored similarly in $12 \mathrm{mM}$ Hepes-KOH, $\mathrm{pH} 7.5,50 \mathrm{mM} \mathrm{KCl}, 6 \mathrm{mM}$ $\mathrm{MgCl}_{2}, 5 \mathrm{mM} \mathrm{ZnSO}$, $0.05 \%$ Nonidet P-40, $1 \mathrm{mM}$ DTT, and $50 \%$ glycerol.

Electrophoretic mobility shift assay (EMSA) and supershift analysis. In vitro binding reactions between oligonucleotides and nuclear extract were done in a total volume of $20 \mu \mathrm{l}$ containing: $2 \mu \mathrm{l}$ of $10 \times$ binding buffer $(0.1 \mathrm{M}$ Tris- $\mathrm{HCl}, \mathrm{pH} 7.5,50 \%$ glycerol, $10 \mathrm{mM}$ EDTA,
$10 \mathrm{mM}$ dithiothreitol), $1 \mu \mathrm{l}$ of $1 \mathrm{mg} / \mathrm{ml}$ poly(dI.dC) (Sigma Chemical Co.), $1 \mu \mathrm{l}$ of $1 \mathrm{mg} / \mathrm{ml}$ salmon sperm DNA (Sigma Chemical Co.), $3 \mu \mathrm{l}$ of nuclear extract (normalized to $\sim 8 \mathrm{mg} / \mathrm{ml}$ of total protein), and $1 \mu \mathrm{l}$ radiolabeled oligonucleotide (specific activity 50,000 $\mathrm{cpm} /$ reaction). Binding reactions involving recombinant proteins contained $2 \mu \mathrm{l}$ of the appropriate dilution and $1 \mu \mathrm{l}$ of $1 \mathrm{mg} / \mathrm{ml} \mathrm{BSA}$ as a protein carrier. The reaction was allowed to proceed for $30 \mathrm{~min}$ at $22^{\circ} \mathrm{C}$ before the addition of nondenaturing loading buffer $(0.2 \%$ bromophenol blue, $0.2 \%$ xylene cyanol, $20 \%$ glycerol). Samples were electrophoresed for $\sim 1.5 \mathrm{~h}$. Gels were dried under vacuum and autoradiographed overnight. Supershift studies were performed as above except $1 \mu \mathrm{l}(1$ $\mu \mathrm{g}$ ) of the appropriate antibody (Santa Cruz Biotechnology, Inc., Santa Cruz, CA) was added $10 \mathrm{~min}$ before the addition of radiolabeled oligonucleotide. When appropriate densitometric analysis was completed on the autoradiographs using ImageQuant software (Molecular Dynamics, Sunnyvale, CA).

Statistics. CAT activity relative to HGH transcription of the various constructs was compared by ANOVA; when significant differences were noted among groups, they were compared by Student's $t$ test. Differences in allele frequency among groups were calculated using Fisher's exact test.

\section{Results}

Coding region mutations. Mutations consisting of a change in a single base pair were identified in exon $1(\mathrm{C} \rightarrow \mathrm{T}$ at base 21$)$, exon $2(\mathrm{G} \rightarrow \mathrm{A}$ at base 270$)$, and exon $13(\mathrm{~A} \rightarrow \mathrm{G}$ at base 1,728). At the locus identified in exon 1 there were 6 heterozygotes among the 25 nonaspirin-sensitive asthmatic subjects, 3 among the 6 aspirin-sensitive asthmatic subjects, and 5 heterozygotes among the 25 normal subjects; allele frequencies are given in Table II. At the locus identified in exon 2 there was one heterozygote and one homozygote among the 25 nonaspirin-sensitive asthmatic subjects; this polymorphism was not found in the 6 aspirin-sensitive asthmatic or the 25 normal subjects. At the locus identified in exon 13 there were 4 heterozygotes among the 25 nonaspirin-sensitive asthmatic subjects, none among the 6 aspirin-sensitive asthmatic subjects, and 1 heterozygote and 1 homozygote among the 25 normal subjects. Each of these mutations was conservative in that the amino acid sequence of the putative 5-LO protein derived from the mutant DNA would not be changed. In the sample of DNAs examined there was no significant difference in the allele frequency of each of these mutations between the normal and the asthmatic subjects. Among the 25 normal and 31 asthmatic individuals examined there were no mutations noted by SSCP in exons 3-12 and 14.

Mutations in the 5'-flanking region. Mutations, consisting of a change in a single base pair were noted in the negative regulatory region (as defined by Hoshiko et al. [5]) between positions 1,844 and 1,557 upstream from the ATG translation start site; these consisted of a $\mathrm{G} \rightarrow \mathrm{A}$ substitution at $-1,708$ and a $\mathrm{G} \rightarrow \mathrm{A}$ substitution at $-1,761$. All subjects with the $\mathrm{G} \rightarrow \mathrm{A}$ substitution at $-1,708$ also had the $\mathrm{G} \rightarrow \mathrm{A}$ substitution at $-1,761$. There were six nonaspirin-sensitive asthmatics (heterozygotes), two aspirin-sensitive asthmatics (heterozygotes), and nine (eight heterozygotes and one homozygote) normal subjects with these mutations.

A family of mutations was noted in the transcription factor binding region 212 to 88 bp upstream from the translation start site. The first member of this family of mutations was originally termed a type I mutation by SSCP as defined in Fig. 1. This mutant allele was present in two samples (one homozy- 


\begin{tabular}{|c|c|c|c|c|}
\hline \multirow[b]{3}{*}{ Locus } & \multirow[b]{3}{*}{ Allele type } & \multicolumn{3}{|c|}{ Allele frequency } \\
\hline & & \multicolumn{2}{|c|}{ Type of asthma } & \multirow[t]{2}{*}{ Normal } \\
\hline & & Nonaspirin-sensitive & Aspirin-sensitive & \\
\hline \multirow{3}{*}{$\begin{array}{l}\text { Negative regulatory region } \\
\quad(-1,557 \text { to }-1,844)\end{array}$} & Wild type & $0.88(44 / 50)$ & $0.83(10 / 12)$ & $0.80(40 / 50)$ \\
\hline & $\mathrm{G} 1708 \rightarrow \mathrm{A}$ & $0.12(6 / 50)$ & $0.17(2 / 12)$ & $0.20(10 / 50)$ \\
\hline & $\mathrm{G} 1761 \rightarrow \mathrm{A}$ & & & \\
\hline \multirow{4}{*}{$\begin{array}{l}\text { Transcription factor } \\
\text { binding region }\end{array}$} & Wild type & $0.78(165 / 212)$ & $0.75(9 / 12)$ & $0.76(38 / 50)$ \\
\hline & 12-bp deletion* & $0.06(12 / 212)$ & $0.00(0 / 12)$ & $0.02(1 / 50)$ \\
\hline & 6-bp deletion* & $0.14(30 / 212)$ & $0.25(3 / 12)$ & $0.18(9 / 50)$ \\
\hline & 6-bp addition* & $0.02(5 / 212)$ & $0.00(0 / 12)$ & $0.04(2 / 50)$ \\
\hline \multirow[t]{2}{*}{ Exon 1} & Wild type & $0.88(44 / 50)$ & $0.75(9 / 12)$ & $0.90(45 / 50)$ \\
\hline & $\mathrm{C} 21 \rightarrow \mathrm{T}$ & $0.12(6 / 50)$ & $0.25(3 / 12)$ & $0.10(5 / 50)$ \\
\hline \multirow[t]{2}{*}{ Exon 2} & Wild type & $0.94(47 / 50)$ & $1.00(12 / 12)$ & $1.00(50 / 50)$ \\
\hline & $\mathrm{G} 270 \rightarrow \mathrm{A}$ & $0.06(3 / 50)$ & $0.00(0 / 12)$ & $0.00(0 / 50)$ \\
\hline \multirow[t]{2}{*}{ Exon 13} & Wild type & $0.92(46 / 50)$ & $1.00(12 / 12)$ & $0.94(47 / 50)$ \\
\hline & $\mathrm{A} 1728 \rightarrow \mathrm{G}$ & $0.08(4 / 50)$ & $0.00(0 / 12)$ & $0.06(3 / 50)$ \\
\hline
\end{tabular}

Allele frequencies in the nonaspirin-sensitive asthmatic subjects are given for the 25 patients with immortalized DNA and the 81 patients from whom cheek brushings were available. *Location of the additions/deletions identified in the text.

gote and one heterozygote) of immortalized lymphocyte DNA from nonaspirin-sensitive asthmatic subjects and one normal subject (heterozygote); it was not identified in any aspirin-sensitive asthmatic subjects. Direct cycle sequencing of the DNA obtained from the individual homozygous for this mutant allele, Fig. 2, indicated the presence of a 12-bp deletion, $-\mathrm{GGG}$ CGG GGG CGG - from the wild-type sequence between positions -165 and -176 . Interestingly, this deletion consisted of two of the known five tandem repeats of the consensus Sp1 binding sequence (16-18), which are present between 147 and 176 bp upstream from the ATG start site of the 5-LO gene.

The DNA from individuals harboring the type II mutation in Fig. 1 was resolved using automated sequencing as a 6-bp deletion consisting of a loss of a single Sp1 and Egr-1 binding

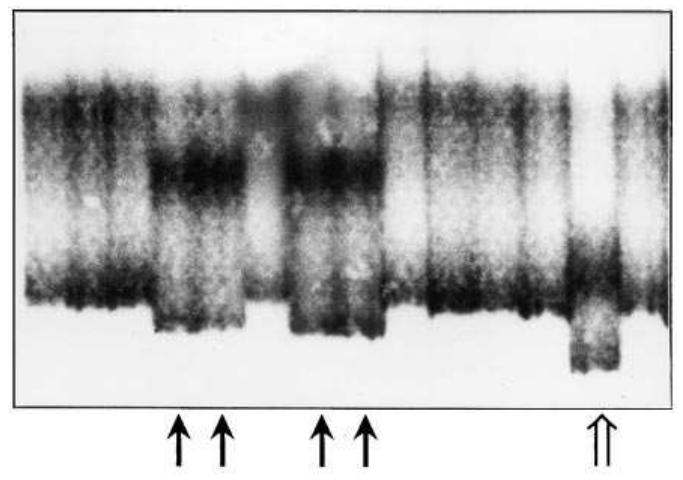

\section{介 Type I Polymorphism \\ $\uparrow$ Type II Polymorphism}

Figure 1. SSCP analysis of DNA from patients with mild-to-moderate asthma. Two types of polymorphism were identified as indicated by the double arrow (type I) and the single arrow (type II). The patient with the type I polymorphism is homozygous at this locus while the patients with the type II polymorphism are each heterozygous at this locus. motif between positions -171 and -176 . Because these mutations, i.e., a deletion of one and two Sp1 or Egr-1 binding motifs, substantially modified the length of the DNA fragments obtained by PCR, we screened genomic DNA from an addi-

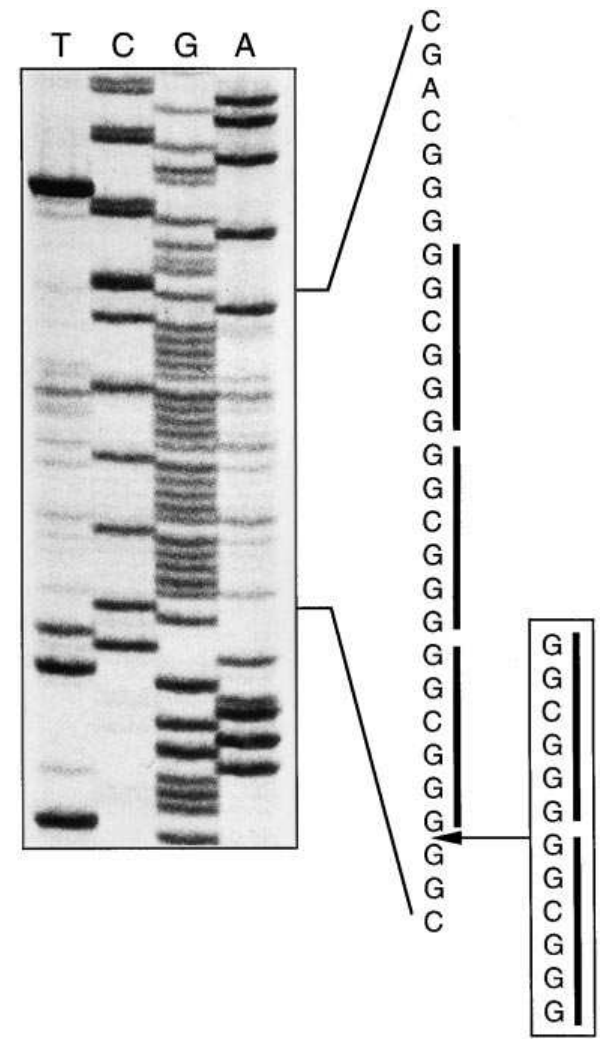

Figure 2. Direct cycle sequencing of DNA from the patient indicated as possessing the type I polymorphism shown in Fig. 1. The sequence read from the ladder is shown at the right the figure and matches the archival sequence but is missing 12 bp (inset); Sp1 binding motifs (solid bar, right). The missing DNA consists of the loss of two Sp1 binding motifs. 


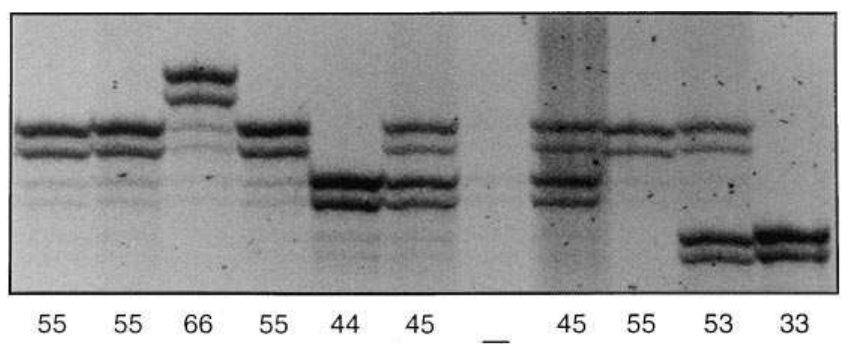

Figure 3. SSLP analysis of DNA from subjects with all four alleles identified in this study. Alleles are identified by the two digit number below each lane where each digit indicates the number of Sp1 binding motifs. Type 55 is the wild type while all others are mutants. Type 66 is from an individual homozygous for the 6-bp addition, 44 from an individual homozygous for the 6-bp deletion, and 33 from an individual homozygous for the 12-bp deletion. DNA from individuals heterozygous for these mutations are also shown.

tional 81 asthmatics using SSLP. This led to the identification of a third mutant form of DNA, Fig. 3, identified by automated sequencing as a 6-bp addition of a Sp1 binding domain. The mutant alleles identified at this locus are compared to the wildtype sequence in Fig. 4. Among the 61 individuals from whom immortalized DNA was available, there were 23 individuals harboring mutant alleles as indicated by SSLP. In 14 of these individuals the inferred mutation was confirmed by automated sequencing (data not shown).

Haplotypic inferences. When DNA sequences from the wild type and mutant DNA sequences were compared, it was determined that individuals heterozygous or homozygous for the 12-bp deletion were also heterozygous or homozygous for the mutation noted in exon 2, respectively. Similarly we determined that individuals heterozygous or homozygous for the 6-bp deletion were also heterozygous or homozygous for the mutation noted in exon 1 . These findings are consistent with the presence of a haplotype in which the 6- and 12-bp transcription factor binding region mutations are in linkage disequilibrium with the previously noted exon 1 and exon 2 mutations, respectively.

CAT reporter assays. To determine whether functional differences existed among the various forms of the 5-LO tran-

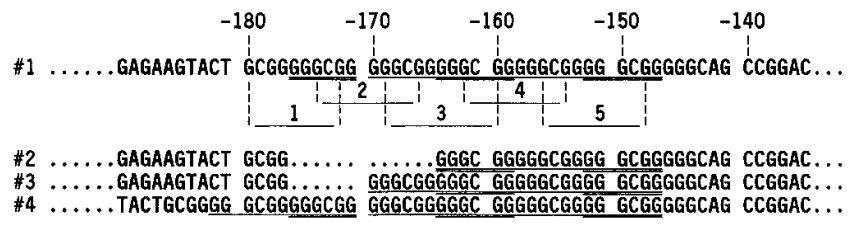

Figure 4. Location of the polymorphisms identified in the transcription factor binding region of the 5-LO gene. Numbering applies only to the normal sequence and is registered such that the A of the ATG start codon is +1 . Sp1 binding motifs (GGGCGG) are shown as single underlined alternating with double underlined. Also shown below sequence 1 are the five interlocking Egr-1 binding motifs; these are numbered 1 through 5 (No. 1) Normal sequence of the tandem Sp1 binding motifs in the transcription factor binding region of the 5-LO gene (No. 2) Sequence with the 12-bp deletion (No. 3) Sequence with the 6-bp deletion (No. 4) Sequence with the 6-bp addition. Because the gene contains five Sp1 binding motifs in tandem, assignment of the specific deletions within the region of tandem repeats is arbitrary. Sequence numbering is from the GENBANK accession \#M38191.Seq Human 5-Lipoxygenase Gene Exon \#1-1/91. scription factor binding region, we constructed a panel of CAT reporter gene constructs containing the wild type, the 12-bp deletion, the 6-bp deletion or the 6-bp addition. The CAT activity in relationship to the activity of the coreporter plasmid pHGH is shown in Fig. 5; data shown are the mean of 5 separate transfections each performed in triplicate. The relative CAT activity of the constructs containing the 12-bp deletion, the 6-bp deletion, or the 6-bp addition was significantly less than the CAT activity of the wild type constructs, $P=0.0047$, $P=0.022$, and $P=0.038$, respectively.

$E M S A$. To further characterize the wild type and mutant forms of the 5-LO transcription factor binding region, EMSAs were used to detect specific DNA-nuclear protein interactions. The ubiquitous transcription factor $\mathrm{Sp} 1$ is known to bind the functionally important $\mathrm{G}+\mathrm{C}$-rich region of the 5-LO promoter (5). The inducible transcription factor Egr-1 shares a similar $\mathrm{G}+\mathrm{C}$-rich consensus binding motif, and Sp1/Egr-1 interactions may be important in the transcriptional regulation of many genes (15). We, therefore, proposed that Egr-1 would also be capable of interacting with the 5-LO G+C-rich sequence as well as Sp1. Moreover, we hypothesized that Sp1 and Egr-1 binding differences may be partially responsible for the functional differences detected with our CAT reporter assays. Because HUVEC are known to produce Sp1 and phorbol myristate acetate (PMA) inducible Egr-1 they were used as a source of nuclear extracts. EMSA with unstimulated HUVEC nuclear extract produced a single intense band (Fig. $6 A$ ). Nuclear extract from PMA-stimulated cells produced the original band plus a more mobile lower band of similar intensity. Nuclear extract prebound to anti-Sp1 antibodies supershifted the upper band, whereas anti-Egr-1 antibodies supershifted the lower band. Identical concentrations of antibodies to Sp4 and ETS (a nuclear binding protein with transactivating properties) factors

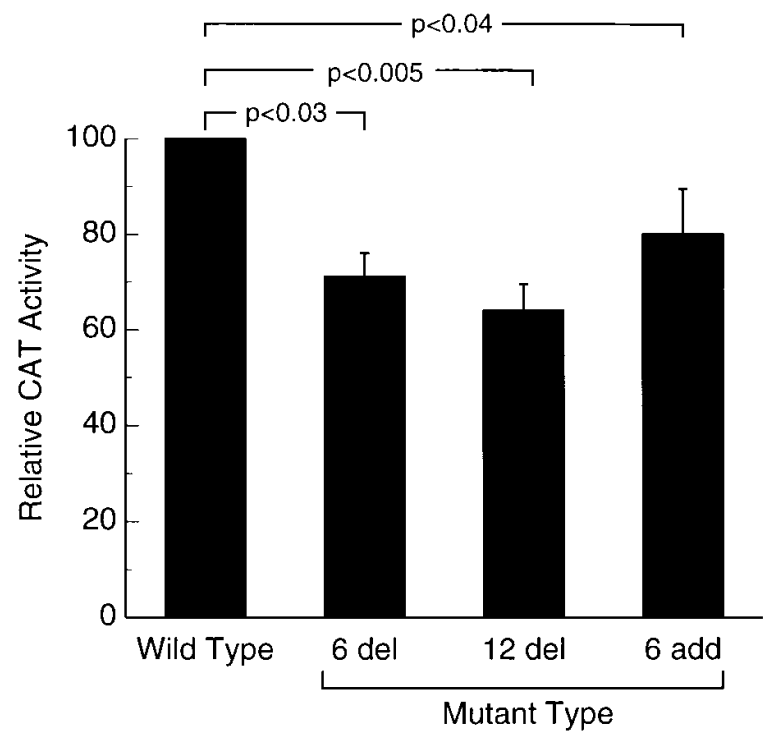

Figure 5. Relative CAT activity, corrected for transfection efficiency, of HeLa cells transfected with pCAT inserts containing either wildtype 5-LO upstream DNA (assigned a value of 100) or mutant DNA isolated by PCR from subjects harboring the 12-bp deletion, the 6-bp deletion and the 6-bp addition. The capacity of the mutant forms of DNA to promote transcription of the CAT reporter constructs was significantly less than that of the wild type DNA. Results are the mean of five experiments each performed in triplicate. 

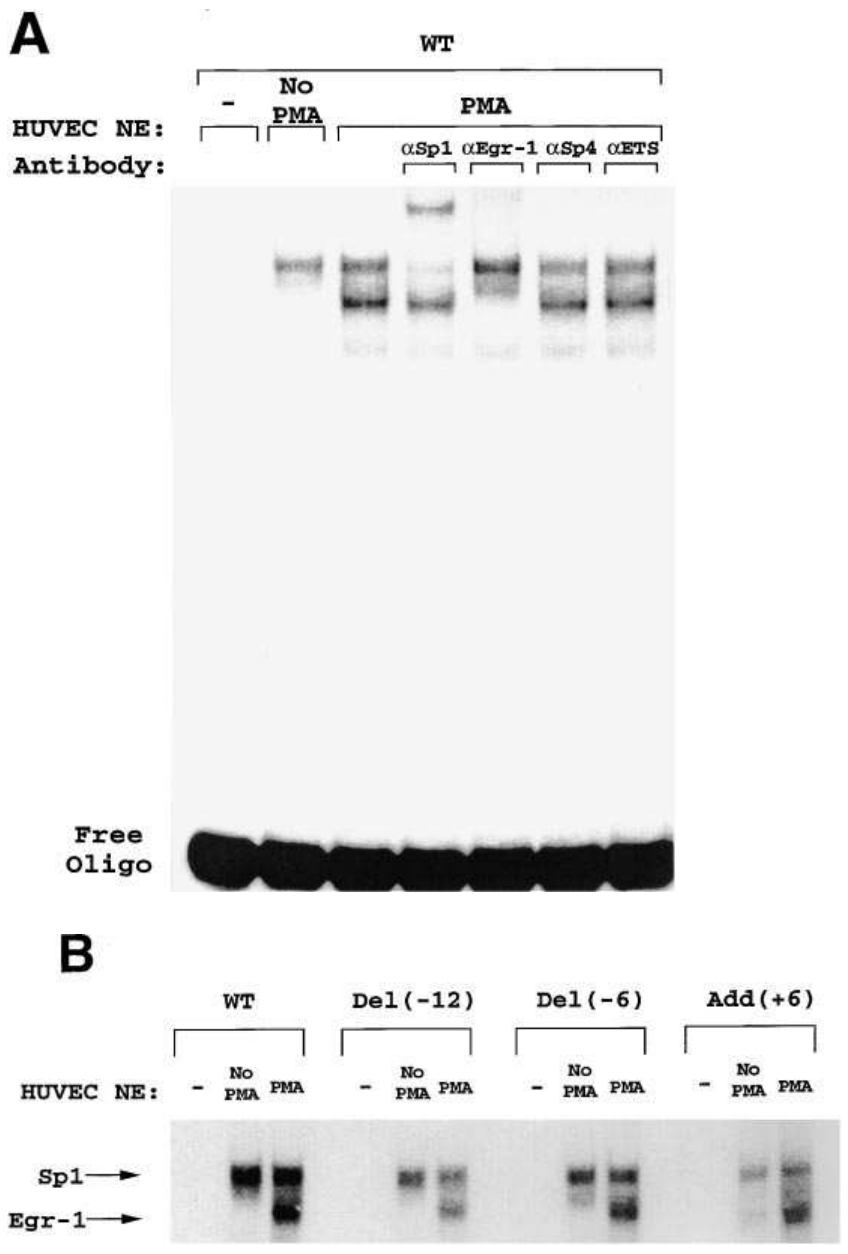

Figure 6. EMSA and supershift analysis of nuclear proteins from HUVECs with radiolabeled wild-type oligonucleotide. $(A)$ No bands are seen in the absence of nuclear extract, and the radiolabeled wild type migrates to the bottom of the gel. Unstimulated cells (no PMA) produce essentially one intense band that supershifts with the addition of anti-Sp1 antibodies. PMA-stimulated cells produce an additional lower band that supershifts with anti-Egr-1 antibodies. Control antibodies to Sp4 and ETS (a nuclear binding protein with transactivating properties) proteins produce no change in the intensity or position of bands. $(B)$ All three mutant oligonucleotides are capable of binding Sp1 and inducible Egr-1. Specific activity and quantity of nuclear extract were equivalent for each oligonucleotide. The intensity of bands produced by wild type is greater than that of bands produced by the mutant forms.

produced no change. These data suggest that $\mathrm{Sp} 1$ and inducible Egr-1 are capable of binding the wild type $\mathrm{G}+\mathrm{C}$-rich region of 5-LO.

EMSAs with the three mutant $\mathrm{G}+\mathrm{C}$-rich regions demonstrated that they are also capable of binding Sp1 and inducible Egr-1 (Fig. 6 B). There were differences in the intensity and location of the Sp1 and Egr-1 bands among the different mutant DNAs. Sp1 and Egr-1 from nuclear extracts bound the wild type sequence with greater intensity than the mutant sequence; the relative intensity for mutants for $\mathrm{Sp} 1$ was 47 to $54 \%$ of the wild type while the relative intensity for Egr-1 was 42 to $67 \%$ of the wild type. Recombinant Egr-1 (Fig. 7) and Sp1 (data not shown) are capable of binding all four oligonucleotides. Increasing concentrations of Egr-1 in proportion to radiolabeled oligonucleotide produced multiple bands with dif- ferences in the pattern of binding between wild and mutant oligonucleotides. The mutant consisting of a 6-bp addition produced three bands of greatest intensity, whereas the wild type and other mutants produced only two bands of lesser intensity. The wild type and 6-bp deletion oligonucleotides bound slightly more intensely than the 12-bp deletion oligonucleotide. Recombinant Sp1 produced only one intense band and there were no obvious differences in binding intensity between the different oligonucleotides.

\section{Discussion}

5-LO catalyzes the formation of leukotriene (LT) $\mathrm{A}_{4}$ from arachidonic acid. Hoshiko et al. (5) have shown, using HeLa and HL60 cells transfected with CAT reporter constructs with various regions of the 5-LO promoter deleted, that 5-LO expression is dependent on the presence of a $\mathrm{G}+\mathrm{C}$-rich transcription factor binding region (212-88 bp upstream from the ATG start site); this region contains a number of nucleotide sequences consistent with binding motifs for a number of well established nuclear binding factors. Our data demonstrate that a number of mutations exist in the 5-LO gene; among these are a family of mutations in which the number of Sp1 and Egr-1 binding motifs in the transcription factor binding region is altered. Each of these mutant upstream 5-LO regions is significantly less efficient than the wild type in directing transcription of the CAT reporter gene, Fig. 5. In addition, EMSA analysis using DNA fragments containing the wild-type and variant multiple tandem Sp1 and Egr-1 binding motifs demonstrated that each form of the DNA could specifically bind to recombinant Sp1 and Egr-1 and induced Egr-1 from HUVECs. Subtle differences in transcription factor binding among the wild-type and mutant forms of DNA were detected. Our data are consistent with the hypothesis that naturally occurring 5-LO promoter mutations alter transcription factor binding and may play a role in 5-LO gene expression in vivo.

Three mutations were identified within the protein encoding region; these were in exon $1(\mathrm{C} \rightarrow \mathrm{T}$ at base 21$)$, in exon 2 $(\mathrm{G} \rightarrow \mathrm{A}$ at base 270$)$, and in exon $13(\mathrm{~A} \rightarrow \mathrm{G}$ at base 1,728). Each of these mutations was conservative in that it would not modify the amino acid sequence of the protein encoded by it and none of the mutations were located in a position that would likely modify the capacity of cells to appropriately splice intronic RNA. Because we surveyed 50 nonasthmatic alleles and 62 asthmatic alleles and found no DNA mutations that would modify the structure of the 5-LO protein, we can estimate, based on the assumption that mating is random with respect to these loci, with $95 \%$ confidence (i.e., $P<0.05$ ), that if such alleles exist their frequency is $<7.1 \%$ in the nonasthmatic US population and $<5.8 \%$ in the asthmatic population. We found no mutations shared by six patients with aspirin-sensitive asthma, indicating that there is unlikely to be a single genetic abnormality in 5-LO common to patients with this disorder $(6,19,20)$. These data indicate that the mutations identified in the protein encoding region of the 5-LO gene are unlikely to have functional consequences with respect to the etiology of asthma in general or aspirin-sensitive asthma in particular.

In contrast to these mutations without likely functional consequences, we identified a family of mutations in the transcription factor binding region 212-88 bp upstream from the translation start site of the 5-LO gene, as defined by Hoshiko et al. (5). This $\mathrm{G}+\mathrm{C}$-rich region contains a number of nucle- 


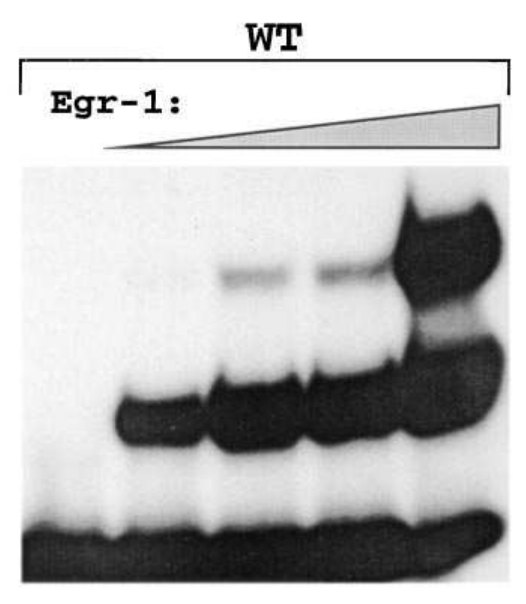

$\operatorname{Del}(-6)$

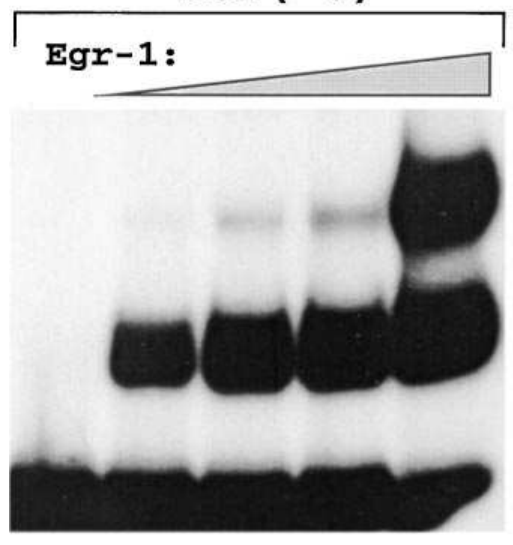

$\operatorname{Del}(-12)$

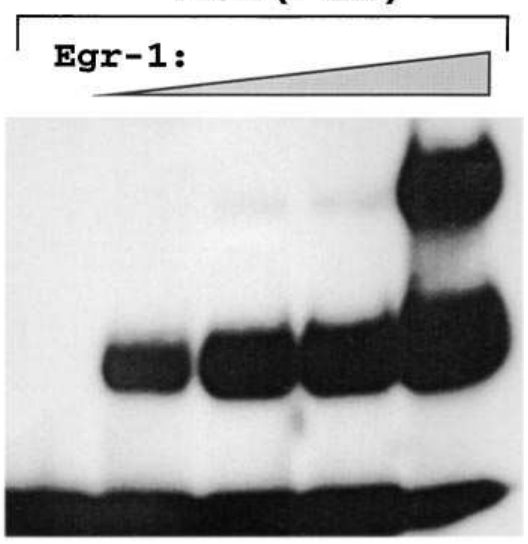

Add (+6)

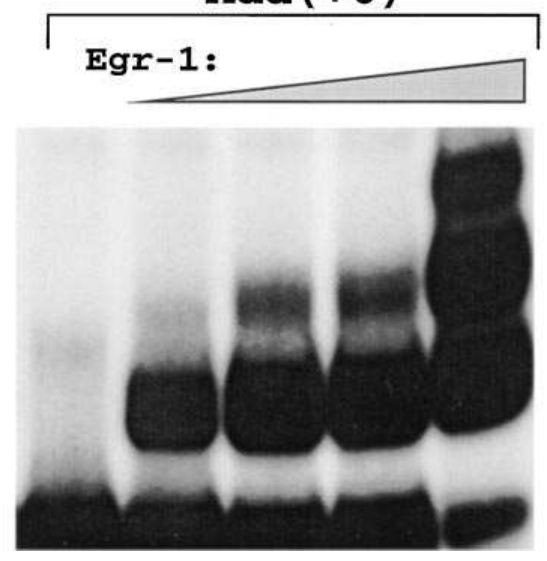

Figure 7. EMSA using recombinant Egr-1 (zinc finger region) in increasing concentrations $(0,1: 500,1: 200,1: 50,1: 10)$. Specific activity and quantity of protein were equivalent for each oligonucleotide. The oligonucleotide coinciding with 6-bp addition mutation, Add $(+6)$, produces three bands; all other oligonucleotides produce only the faster migrating, lower two bands. This oligonucleotide also produces the bands of greatest intensity while the oligonucleotide corresponding to the deletion of 12-bp, $\operatorname{Del}(-12)$, produces the bands of lowest intensity. otide sequences which match established consensus binding motifs for transcription factors. Hoshiko et al. demonstrated that reporter gene constructs which did not contain this region of the 5-LO gene were less efficient in promoting the transcription of CAT reporter gene activity than constructs containing the wild-type nucleotide sequence. This promoter region contains $10 \mathrm{Sp} 1$ binding motifs, five of which occur in a single tandem repeat of the consensus binding motif. They also demonstrated, using EMSAs, that Sp1 could bind to this region of DNA, suggesting that $\mathrm{Sp} 1$ binding was a critical component required for 5-LO gene transcription. Survey of this region for consensus binding sequences is also notable for the presence of 5 Egr- 1 binding sequences overlapping the $5 \mathrm{Sp} 1$ binding sites. Recent studies suggest that Sp1/Egr-1 interactions within $\mathrm{G}+\mathrm{C}$-rich promoter sequences may play an important role in inducible gene expression (15). It is possible that the affinity or number of Sp1/Egr-1 binding sites may serve to alter gene transcription.

Our data demonstrate the presence of a naturally occurring family of alleles in this transcription factor binding region which are characterized by deletion or addition of consensus Sp1 (-GGGCGG) and Egr-1 (-GCGGGGGCG-) binding motifs. We demonstrate that each of the variant alleles can bind Sp1 and Egr-1 protein as indicated by EMSA using recombinant protein and supershift analysis with nuclear extract and that each is less effective than the wild-type allele in reporter gene assays. It is tempting to speculate that the mutant alleles have decreased affinity or number of viable binding sites for Sp1/Egr-1, accounting for weaker reporter activity. Interestingly, Egr-1 appears to bind the 6-bp addition mutant oligonucleotide with greatest affinity and number of binding sites. It remains to be determined if individuals whose genes contain the mutant forms of 5-LO DNA have altered 5-LO expression and, if so, the mechanism by which this occurs.

We have a number of reasons to believe that the mutations identified are not artifacts arising from the viral immortalization of the cells used as our primary source of DNA or from the PCR amplification of the DNA. With respect to cell immortalization we were able to identify the same mutations whether we used template DNA isolated from immortalized cell lines or obtained by buccal brushing. With respect to PCR amplification we found that individuals with the 6-bp deletion, which is located $\sim 170$ bp upstream from the ATG start site, also had mutant alleles in exon 1 (at a locus 21 bp downstream from the ATG start site) indicating that these mutations are in linkage disequilibrium. Similarly individuals with the 12-bp deletion had mutant alleles in exon 2. Because each of these coding region mutations was identified with a set of PCR primers distinct from the primers used to identify the Sp1/Egr-1 binding motif mutations, it seems unlikely that our findings represent a PCR artifact.

$\mathrm{Sp} 1$ is a zinc finger protein which binds to $\mathrm{G}+\mathrm{C}$ rich DNA sequences (21); one of the consensus binding motifs for Sp1 has been delineated as GGGCGG (16-18). Egr-1 is a member of the immediate early gene family and is also a zinc finger protein with a similar consensus binding motif, namely GCG- 
GGGGCG. Sp1 and Egr-1 binding have been shown to subsequently modify the transcription of DNA located downstream from its binding site. Sp1 binding motifs are commonly found in tandem repeats, with over 35 gene sequences reported in which there are four or more $\mathrm{Sp} 1$ binding motifs in tandem. Despite the frequency with which Sp1 tandem binding motifs occur, there have been no prior reports of DNA mutations characterized by deletion and insertion of the consensus binding motif by itself. There have been reports of mutations in which $\mathrm{Sp} 1$ binding motifs are present in varying copy numbers as a result of insertion or deletion of larger DNA fragments $(22,23)$ or modifications within the Sp1 binding motif itself $(24,25)$. It remains to be determined if the mutations that we have identified will have an appreciable functional impact in vivo.

Indeed, it is interesting to speculate on the possible functional significance of the Sp1/Egr-1 binding motif mutations. For example, although it has been established that treatment of asthmatic patients with agents that have the capacity to interrupt the 5-LO pathway has an overall salutary effect on disease control in patients with asthma, there is substantial heterogeneity among these individuals in their therapeutic response. If there were differences among individuals in their capacity to express 5-LO, then it is possible that these differences could be reflected in the capacity of agents which interrupted the 5-LO pathway to modulate asthmatic responses. Our identification of a family of alleles with altered Sp1/Egr-1 DNA binding motifs and transcription factor binding, which may function to differentially regulate reporter gene activity, provides a potential way to link a given patient's clinical response to treatment modifying the 5-LO pathway and their genotype at the 5-LO locus.

\section{References}

1. Samuelsson, B. 1983. Leukotrienes: mediators of immediate hypersensitivity reactions and inflammation. Science (Wash. DC). 220:568-575.

2. Samuelsson, B., S.E. Dahlen, J.A. Lindgren, C.A. Rouzer, and C.N. Serhan. 1987. Leukotrienes and lipoxins: structures, biosynthesis, and biological effects. Science (Wash. DC). 237:1171-1176.

3. Lewis, R.A., K.F. Austen, and R.J. Soberman. 1990. Leukotrienes and other products of the 5-lipoxygenase pathway. Biochemistry and relation to pathobiology in human diseases. N. Engl. J. Med. 323:645-655.

4. Funk, C.D., S. Hoshiko, T. Matsumoto, O. Radmark, and B. Samuelsson. 1989. Characterization of the human 5-lipoxygenase gene. Proc. Natl. Acad. Sci. USA. 86:2587-2591.

5. Hoshiko, S., O. Radmark, and B. Samuelsson. 1990. Characterization of the human 5-lipoxygenase gene promoter. Proc. Natl. Acad. Sci. USA. 87:9073-9077.

6. Israel, E., A.R. Fischer, M.A. Rosenberg, C.M. Lilly, J.C. Callery, J. Sha- piro, J. Cohn, R. Rubin, and J.M. Drazen. 1993. The pivotal role of 5-lipoxygenase products in the reaction of aspirin-sensitive asthmatics to aspirin. Am. Rev. Respir. Dis. 148:1447-1451.

7. Sugden, B., and W. Mark. 1977. Clonal transformation of adult human leukocytes by Epstein-Barr virus. J. Virol. 23:503-508.

8. Neitzel, H. 1986. A routine method for the establishment of permanent growing lymphoblastoid cell lines. Hum. Genet. 73:320-326.

9. Orita, M., Y. Suzuki, T. Sekiya, and K. Hayashi. 1989. Rapid and sensitive detection of point mutations and DNA polymorphisms using the polymerase chain reaction. Genomics. 5:874-879.

10. Weber, J.L., and P.E. May. 1989. Abundant class of human DNA polymorphisms which can be typed using the polymerase chain reaction. Am. J. Hum. Genet. 44:388-396.

11. Maniatis, T., E.F. Fritsch, and J. Sambrook. 1982. Molecular Cloning, A Laboratory Manual. Cold Spring Harbor Laboratory, Cold Spring Harbor, NY.

12. Finn, P.W., C.J. Kara, J. Douhan, T.T. Van, V. Folsom, and L.H. Glimcher. 1990. Interferon gamma regulates binding of two nuclear protein complexes in a macrophage cell line. Proc. Natl. Acad. Sci. USA. 87:914-918.

13. Ausubel, F.M., R. Brent, R.E. Kingston, J.G. Seidman, J.A. Smith, and K. Stuhl. 1993. Current Protocols in Molecular Biology. John Wiley \& Sons Inc., New York.

14. Dignam, J.D., R.M. Lebovitz, and R.G. Roeder. 1983. Accurate transcription initiation by RNA polymerase II in a soluble extract from isolated mammalian nuclei. Nucleic Acids Res. 11:1475-1489.

15. Khachigian, L.M., V. Linder, A.J. Williams, and T. Collins. 1996. Egr-1induced endothelial gene expression: a common theme in vascular injury. Science (Wash. DC). 271:1427-1431.

16. Karin, M., A. Haslinger, H. Holtgreve, R.I. Richards, P. Krauter, H.M. Westphal, and M. Beato. 1984. Characterization of DNA sequences through which cadmium and glucocorticoid hormones induce human metallothioneinIIA gene. Nature (Lond.). 308:513-519.

17. Ishii, S., J.T. Kadonaga, R. Tjian, J.N. Brady, G.T. Merlino, and I. Pastan. 1986. Binding of the Sp1 transcription factor by the human Harvey ras1 proto-oncogene promoter. Science (Wash. DC). 232:1410-1413.

18. Harrington, M.A., P.A. Jones, M. Imagawa, and M. Karin. 1988. Cytosine methylation does not affect binding of transcription factor Sp1. Proc. Natl. Acad. Sci. USA. 85:2066-2070.

19. Christie, P.E., C.M. Smith, and T.H. Lee. 1991. The potent and selective sulfidopeptide leukotriene antagonist, SK\&F 104353, inhibits aspirin-induced asthma. Am. Rev. Respir. Dis. 144:957-958.

20. Dahlen, B., M. Kumlin, D.J. Margolskee, C. Larsson, H. Blomqvist, V.C. Williams, O. Zetterstrom, and S.E. Dahlen. 1993. The leukotriene-receptor antagonist MK-0679 blocks airway obstruction induced by inhaled lysineaspirin in aspirin-sensitive asthmatics. Eur. Respir. J. 6:1018-1026.

21. Berg, J.M. 1992. Sp1 and the subfamily of zinc finger proteins with guanine-rich binding sites. Proc. Natl. Acad. Sci. USA. 89:11109-11110.

22. Haugen, A., D. Mann, C. Murray, A. Weston, and J.C. Willey. 1989. Interleukin-1 alpha gene intron containing variable repeat region coding for the SP1 transcription factor recognition sequence is polymorphic. Mol. Carcinog. 2: 68-71.

23. Bailly, S., F.S. di Giovine, A.I. Blakemore, and G.W. Duff. 1993. Genetic polymorphism of human interleukin-1 alpha. Eur. J. Immunol. 23:12401245 .

24. Schwerin, M., G. von Lengerken, M. Fredholm, K. Christensen, and S. Krause. 1995. DNA polymorphisms in two transcription control elements (SP1and TATA-box) of porcine HSP70.2 gene detected by allele-specific PCR. Anim. Genet. 26:203-204.

25. Sakai, T., N. Ohtani, T.L. McGee, P.D. Robbins, and T.P. Dryja. 1996 Oncogenic germ-line mutations in Sp1 and ATF sites in the human retinoblastoma gene. Nature (Lond.). 353:83-86. 